\title{
Process development for punching extruded PC based materials in cable duct production
}

\author{
Sebastian Friedrich Noller, Anja Pfennig and Roland Heiler* \\ HTW Berlin, Faculty 2: School of Engineering - Technology and Life, 12459 Berlin, Germany
}

\begin{abstract}
Burr and film formation occurring when punching polycarbonate/ acrylonitrile butadiene styrene (PC/ABS) cable ducts is a common problem during manufacturing of cable ducts. However, little knowledge on base materials, their thermal and mechanical behavior as well as their initial processing and finally behavior during cable duct manufacturing is available. Therefore, to improve process reliability and gain knowledge on mechanical and failure behavior necessary initial investigations focus on cable duct usage, different geometric types, polymer materials and the punching process itself. Optical analysis on punched PC/ABS cable duct with burr and film formation and corresponding punch led to definition of the test tool's geometry for subsequent tests. Since the punching process directly influences burr and film formation, it was necessary to design a demo-tool to observe the burr and film origin. Tensile tests at different test speeds focus on in-situ mechanical behavior using coupons taken from industrial cable ducts made of mineral reinforced polycarbonate (PC) and PC/ABS including further additives that are generally used in industry. First results indicate that higher test speeds appear to reduce the influence of the different admixtures on the elongation behavior of PC based materials.
\end{abstract}

\section{Introduction}

\subsection{Cable duct}

Cable ducts are a highly standardized, DIN EN 50085 normed and frequently utilized product used in a variety of applications and industries, such as mechanical engineering, construction of buildings, rail vehicles or switch cabinets. The main function of the cable duct is to keep cables in order. In addition, a certain degree of protection against mechanical impact is achieved, subsequently traceability of individual cables and operational reliability are increased. Cable ducts differ with regard to their geometry, the slot width which is selected depending on the cable cross-section, the geometry of the punch-out, the filling quantity, resistance to temperature and chemicals, behavior in case of fire, type of fixing (e.g. ground holes), mechanical load capacity and material inclusive additives (e.g. flame retardants). Furthermore, there are various accessories for attaching

\footnotetext{
* Corresponding author: Roland.Heiler@htw-berlin.de
} 
the cable duct or fixing the cables within the cable duct. The basic components, however, are the cable duct and the corresponding cover (Figure 1). Materials mainly used in the production of cable ducts are polyvinylchloride (PVC), polyphenylene ether (PPE) and polycarbonate / acrylonitrile butadiene styrene (PC/ABS). [1, 2]



Fig. 1. Geometry of the cable duct and the corresponding cable duct cover

The standard material, however, is PVC. PVC contains the element chlorine from the main group of halogens. The use of polymers containing halogens has become increasingly disreputable in recent years, as halogens can escape into the ambient air in gaseous form at higher temperatures [3]. In contact with water $\left(\mathrm{H}_{2} \mathrm{O}\right)$, halogens form a compound to build an acid. In the case of PVC or chloride ions (Cl-Ions), for example, this would be the hydrochloric acid $(\mathrm{HCl})$. These reactions can occur inside the human body after inhaling a halogen or when extinguishing fire in a burning building.

To prevent the formation of toxic gases and corrosive acids, thermal stabilizers are mixed into the PVC as additives. This works for low to moderate temperatures, but fails in case of temperatures reached within a fire. Thus cable ducts are progressingly made of PC/ABS. Flame retardant PC/ABS types achieve the best rating "v-0" in the international UL94 flame retardancy classification. For example, this is achieved by the toxicologically harmless and halogen free addition of phosphates. [4, 5] Further advantages of PC/ABS are good processability, good mechanical and thermal properties of PC and notch insensitivity of ABS [6].

The optimization of a manufacturing processes requires certain knowledge on the materials behavior. There are numerous PC/ABS variations, which differ in terms of microstructure as well as properties. The properties of PC/ABS strongly depend on the mixing ratio of the individual polymers [7] as well as the processing parameters for blending and extruding. Further influences on the material characteristics are caused by possible additives.

Since the cable duct manufacturers do not provide any information on raw materials, their suppliers or additives, it is difficult to determine the "correct" material composition. Thus common materials for cable ducts were purchased from a chemical supplier and cable ducts from various manufacturers were bought.

\subsection{Punching process}

\subsubsection{General punching process steps}

Punching is a basic plastic sheet cutting process, also known as shearing or die cutting, and exists in various forms. During punching, a piece is cut chip-less from a blank (Figure 2). In this process a blank is inserted into the punching tool and then fixed by the blank holder with its blank holder force (1). The punch then presses onto the material (2) and deforms it in the elastic region of the material (3). Further downward movement of the punch (4) 
deforms the material plastically. The material begins to flow, forming indentations on the upper side of the blank. As soon as the stress in the material rises above its tensile strength, a material separating rupture occurs. Afterwards the blank, the punch-out part, called slug, and the machine abruptly reshape elastically, creating the frequency shown (5). Finally, the punch must overcome the frictional force between the slug and the blank in order to remove the slug, which is usually discarded, bevore moving backwards (6). [8]

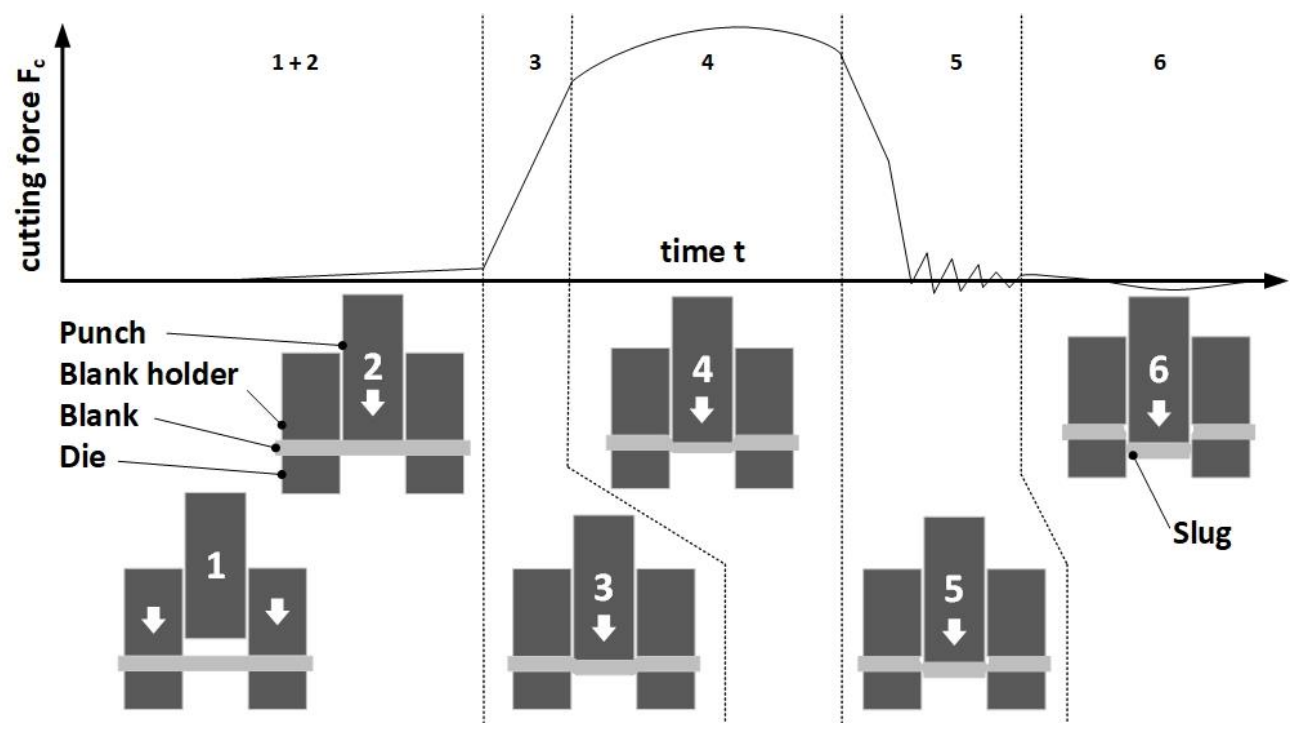

Fig. 2. Punching process steps with corresponding cutting force $F_{C}$ as a function of time $t$

\subsubsection{Conventional punching machines for cable ducts}

In the current production of cable ducts, relatively large punching machines with up to twelvefold tools are used, which leads to comparatively high tool costs. The tools are usually driven hydraulically and therefore carry out slow, energy-intensive punching movements. For some polymers, e.g. PVC, this has a negative effect on the burr and film formation. Thus, an additional deburring process is necessary (Figure 3). This results in additional costs reflected in the product price. In addition, tool changes are costly and timeconsuming, which is reflected in a low flexibility of the machines.



Fig. 3. Schematic cable duct manufacturing process with deburr unit 


\subsubsection{Stanova punching machine "PowerSpee" for cable ducts}

In order to compensate for the disadvantages of conventional punching machines, "Stanova Stanztechnik GmbH" has developed a punching machine that works with single-punchtools (Figure 4). The reduced number of punches is compensated by increasing the stroke frequency. The applied electromechanical eccentric press allows stroke frequencies of up to 900 strokes per minute. Thus the single-punch-tools used are more economical to purchase and store.

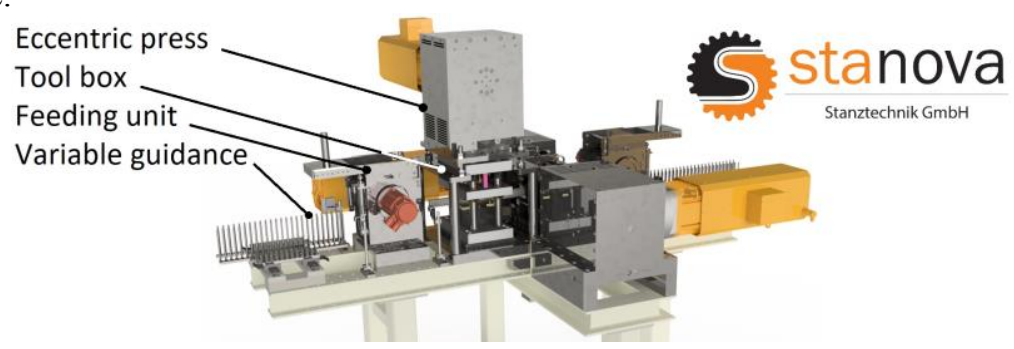

Fig. 4. PowerSpee punching machine [9]

As already mentioned, PVC can be processed without burr and film formation due to high process speed, making a downstream deburring process obsolete. This shortens the production line and thereby frees space for additional production areas. In addition to these advantages, the electromechanical drive works at a higher level of efficiency than previous solutions and is therefore more energy-efficient. Furthermore, the required footprint was reduced by approximately $60 \%$ while at the same time reducing the height of the machine.

(a)

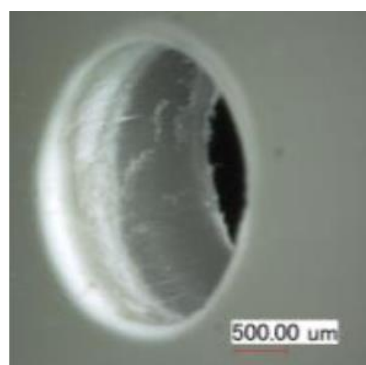

(b)

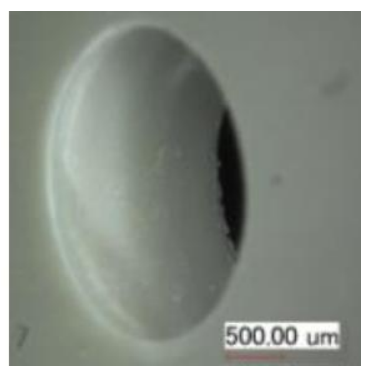

Fig. 5. Burr formation at a punch-out derived from testing PVC at low (a) and high (b) process speed [10]

\section{Materials and Methods}

\subsection{Materials}

Punched PC/ABS cable duct with burr and film formation and corresponding punch were delivered from cable duct producer without material specifications such as mixing ratio, blended additives or present microstructure. Besides this, three different qualities of flame retardant polycarbonate based materials for cable ducts were delivered as extruded, but not punched, cable ducts with corresponding covers. One specified as standard flame retardant $\mathrm{PC} / \mathrm{ABS}$ and two as identical mineral reinforced flame retardant PCs with extrusion speeds of $3 \mathrm{~m} / \mathrm{min}$ and $6 \mathrm{~m} / \mathrm{min}$ (Table 1 ). 
Table 1. Materials used for present investigation

\begin{tabular}{lcc}
\hline Part & Material & Specification \\
\hline Cable duct & PC/ABS & Punched with burr and film formation \\
Punch & Tool steel & Used for punching cable duct above \\
Cable duct & PC/ABS & Un-punched \\
Cable duct & Mineral reinforced PC & Un-punched, extrusion speed $3 \mathrm{~m} / \mathrm{min}$ \\
Cable duct & Mineral reinforced PC & Un-punched, extrusion speed $6 \mathrm{~m} / \mathrm{min}$
\end{tabular}

\subsection{Optical analysis}

The punched PC/ABS cable duct was analyzed regarding burr and film formation using a Keyence VHX 5000 optical microscope (Osaka, Japan). First investigations revealed similarities among all punch-outs. Therefore, two meaningful punch-outs and their respective counterparts were examined precisely.

\subsection{Tensile testing}

According to DIN EN ISO 527 coupons type 1B were taken directly from all three PC based standard cable duct materials. Coupons were taken laterally to the extrusion direction from non-punched cable duct covers. Tensile testing was performed using Zwick/Roell ZMART PRO (Ulm, Germany) with $100 \mathrm{kN}$ nominal power. Stress and strain were observed at room temperature and different testing speeds of $50 \mathrm{~mm} / \mathrm{min}, 100 \mathrm{~mm} / \mathrm{min}$ and $400 \mathrm{~mm} / \mathrm{min}$. Five coupons were tested per velocity and material with the strain being recorded by the traverse movement.

\section{Results and discussion}

\subsection{Burr and film formation}

\subsubsection{Optical analysis of burr and film formation on a PC/ABS cable duct}

Besides previously described advantages gained by using PC/ABS for cable ducts there is a disadvantage regarding the punching process. $\mathrm{PC} / \mathrm{ABS}$ tends to burr and film formation (Figure 6).

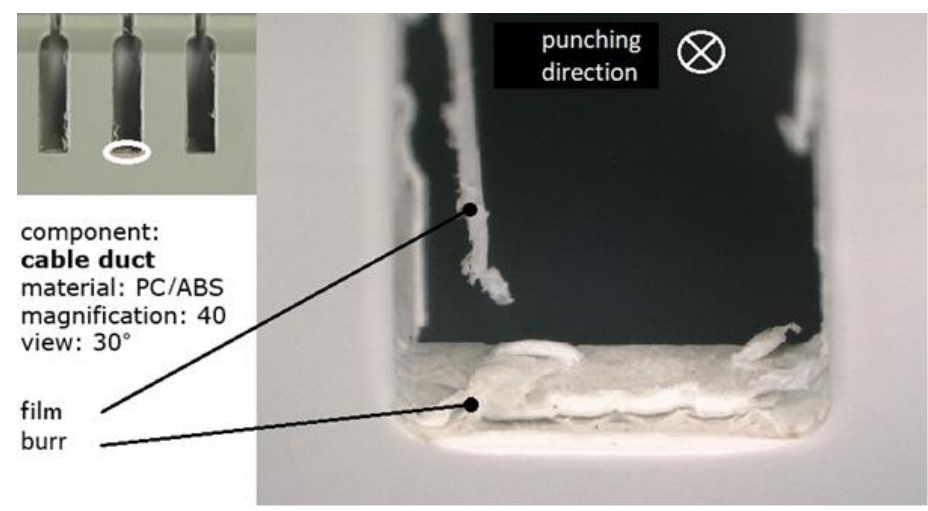

Fig. 6. Burr and film formation at a punch-out of the optically analyzed PC/ABS cable duct 
It was noticed that the actual burr was falsified by the punching process. After the slug is separated from the material by a rupture, the outer surfaces of the punch rub against the inner geometry of the punch-out. This process step is used for smoothing surfaces in the field of metalworking and can increase the surface quality. Whether a similar positive effect occurs with $\mathrm{PC} / \mathrm{ABS}$ is still unknown. After the punching movement, the punch moves out of the punch-out, further falsifying the burr appearance (Figure 7).

When looking at the cross-section of a burr, the burr is bent against the punching direction. In addition, the surface of the inner geometry is divided into two steps. This could indicate an incorrectly set clearance between punch and die, a too brittle behavior of the material or an inhomogeneity inside the material.

A closer look at the film reveals that its shape suggests thermal influence (Figure 8). If the film formation is related to thermal influence, it is unclear whether the film is caused by thermal influence or the heat deforms the film after its formation.

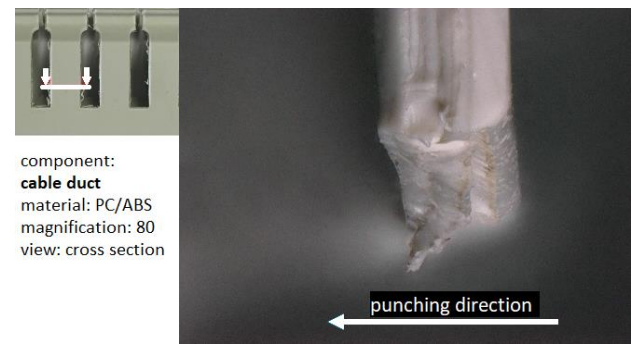

Fig. 7. Cross section of a burr of the optically analyzed PC/ABS cable duct



Fig. 8. Appearance of a film of the optically analyzed PC/ABS cable duct

Further observation regarding the symmetry of the burrs is depicted in Figure 9. The asymmetry is found on all punch-outs investigated and may indicate a non-centric tool die orientation. However, since this is found to be the case on opposite punch-outs on the same side (relative to the tool), one possible explanation is the one-sided reduced stiffness of the profile during the process (Figure 10). During punching out a punch-out, the profile is already processed on one side and unprocessed on the other. The processed side of the profile has a lower stiffness due to the missing material. This probably leads to a one-sided bending away of the material on the processed side during the current punch movement.

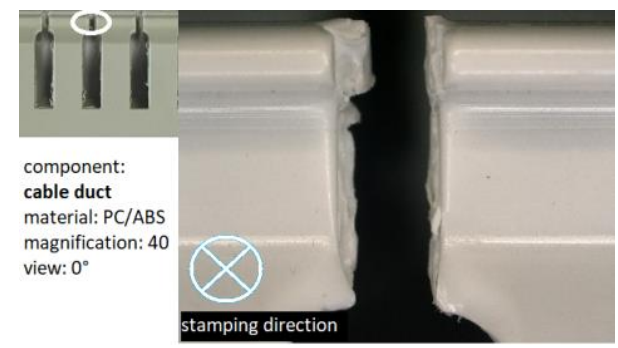

Fig. 9. Asymmetry of burr formation of the optically analyzed PC/ABS cable duct

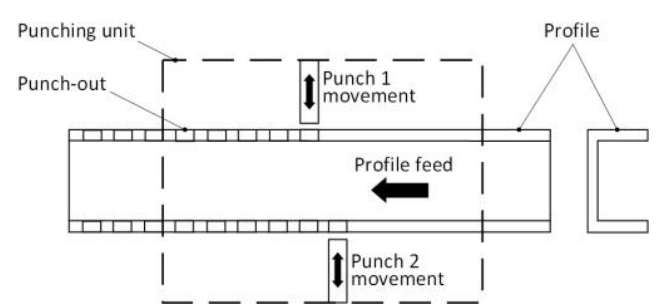

Fig. 10. Punch-out caused one-sided reduced stiffness of profiles during punching process

\subsubsection{Hypotheses and approaches on burr and film formation}

It is assumed that several causes lead to the burr and film formation described. Derived from optical analysis three causes are possible: 
- The main cause for the step-shaped inner surface of the punch-outs may most likely be a wrong dimensioned clearance [11]. This still has to be proven using a test tool and by the variation of the clearance (chapter 3.3).

- The formation of film is probably caused by friction between the tool's surface and the inner surface of the punch-out. The variation of the tool surface quality may lead to confirmation.

- The differences in stiffness of the profile arousing during the process result in an asymmetry of the burr and film formation. A possible solution is an increase of the holding force.

\subsection{Analysis of tool geometry}

As the tools generate relatively high tool costs due to their complex geometry, their geometry is unsuitable for larger quantities of test tools. Therefore, the geometry of the tools was analyzed and abstracted (Figure 11). The geometry is a combination of two squares, four radii and two overhangs.


Fig. 11. Abstraction of a tool (punch) geometry used in cable duct production

On the basis of the optical burr and film analysis, burr critical areas of the tool were identified in order to transfer them into a test tool. The optical analysis revealed that there were no differences between squares S1 and S2. This results in the fact that a rectangular basic geometry is sufficient for the test tool. The radii R1 and R2 are also burr critical and must therefore be present on the test tool. In the area of the overhangs $\mathrm{O} 1$ and $\mathrm{O} 2$ no special characteristics were observed. Therefore, the test tools were defined using a rectangular geometry with four different radii and without overhangs (Figure 12). The test tools will be used to investigate the general burr and film formation using design of experiments (DoE). The results will subsequently be transferred to a real tool.

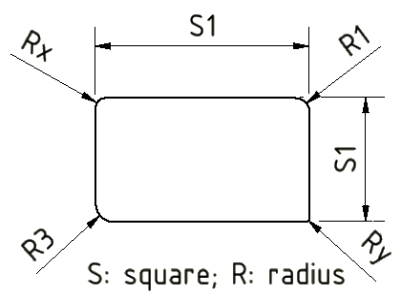

Fig.12. Derived cross section of the geometry of the test tool 


\subsection{Demo-tool for process visualization}

Since the real punching tool is not transparent, only hypotheses regarding the burr and film formation respectively the causes for this can be made based on the end product. In order to better understand burr and film formation and to assign the individual faults to their respective causes a demo-tool was designed. The special feature here is the one-sided recess of the die and the corresponding intake (Figure 13). Through the recess, the burr and film formation can be observed during the punching process. Since the process is almost instantaneous, a high-speed camera Redlake MotionPro HS-4 (Cheshire, USA) is used for observation. [12]

After analyzing the camera images, the individual process steps can be identified and assigned to corresponding snapshots. This allows to verify or refine the hypotheses on the origin of burr and film formation. In addition, the influence of the clearance on the burr and film formation should be visualized. For this reason, three demo dies with varied clearance were manufactured.



Fig. 13. Demo-tool

\subsection{Tensile Testing}

As mentioned before, the tensile strength of the material is exceeded during the stamping process resulting in a material failure by rupture. Furthermore, depending on its elongation behavior, material can get into the clearance and cause burrs [13].

Strain at tensile strength $\varepsilon_{\mathrm{m}}$ with low standard deviations for all subjected materials and performed test speeds is demonstrated in Figure 14. Strain rises with increasing test speed from $50 \mathrm{~mm} / \mathrm{min}$ to $100 \mathrm{~mm} / \mathrm{min}$ and decrease with a change in test speed from 100 $\mathrm{mm} / \mathrm{min}$ to $400 \mathrm{~mm} / \mathrm{min}$. Slightly lower values were detected for mineral reinforced materials and higher extrusion speed.

Relatively similar values, approximately $10 \%$, for strain at break $\varepsilon_{\mathrm{tb}}$ are given in Figure 15 for mineral reinforced PC materials independent of the test speed applied. PC/ABS has relatively high average values with large standard deviations at low test speeds. At a test speed of $400 \mathrm{~mm} / \mathrm{min}$, however, this effect disappears and PC/ABS exhibits behavior similar to that of mineral reinforced PC. 


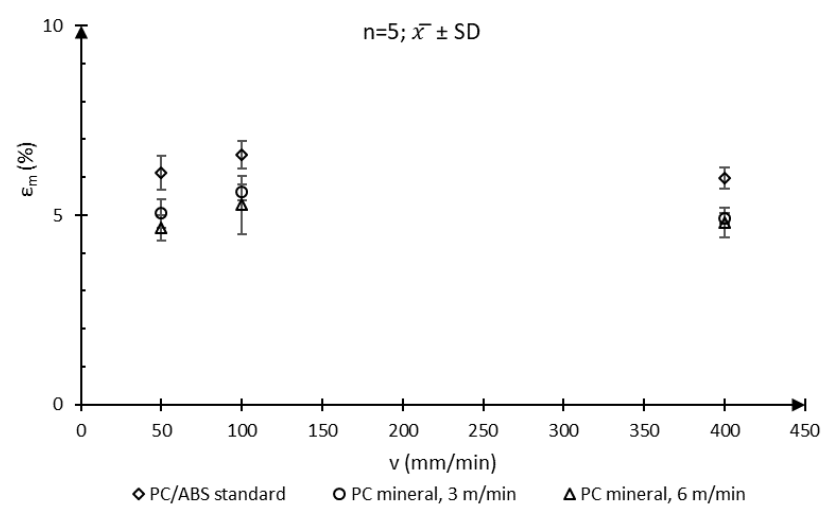

Fig.14. Strain at tensile strength derived from tensile testing as a function of speed during testing

Since high elongation values encourage entry of the material into the clearance, high process speeds seem to be beneficial for the punching process of the PC/ABS. In addition, the elongation values are more predictable at higher speeds which is important for adapting a process to a material.

Stresses associated with the elongation values were not discussed here, as they range in relatively small dimensions that can easily be mastered by the punching machine.



Fig. 15. Strain at break derived from tensile testing as a function of speed during testing

\section{Further investigations}

Further investigations will focus on additional PC/ABS materials purchased in the shape of cable ducts. All materials will be subjected to tensile and Vickers hardness tests. In addition, materials that can be purchased in required thickness are tested with Charpy impact test. Simultaneously, SEM investigation is intended to provide information on the mixing ratio of $\mathrm{PC}$ to ABS. Failure mechanisms of PC/ABS depend on whether the continuous phase consists of $\mathrm{PC}$ or $\mathrm{ABS}$ or whether a 50/50 mixture is present. For a later optimization of the tools probably different parameters regarding the mixing ratios have to be fulfilled. This information should help to define the factor levels of the aspired DoE. Various tools, process and material parameters will be varied in order to prevent burr and film formation in future punching processes of PC/ABS. 
Supported by:



on the basis of a decision

by the German Bundestag

The authors would like to acknowledge Federal Ministry of Economic Affairs and Energy for funding, master's degree candidate Yasin Baki for performing the experiments and laboratory engineer Katharina Becker for her support during materials testing. We would also like to thank our cooperating partner Stanova Stanztechnik $\mathrm{GmbH}$ for providing helpful information.

\section{References}

1. Obo Bettermann Vertrieb Deutschland GmbH \& Co. KG 2018 Verdrahtungskanäle 9138880 04/2018 DE

2. HellermannTyton GmbH 2017 Mehr Raum für Effizienz im Schaltschrankbau: Mit Kabelmanagementlösungen von HellermannTyton 03/2017 031-93374

BRO Schaltschrankbau

3. Sze On Chan H 1984 J. Fire Sci. 2 106-22

4. Perret B, Pawlowski K H and Schartel B 2009 J. Therm. Anal. Calorim. 97 949-58

5. Green J 1991 J. Fire Sci. 9 285-95

6. Inberg J P F 2001 Dissertation: Fracture of polycarbonate/ABS blends (Enschede: University of Twente)

7. Krache R and Debah I 2011 J. M. S. A. 02 404-10

8. Nothhaft K 2013 Dissertation: Schwerschneiden höchstfester Blechwerkstoffe im offenen Schnitt (München: TU München)

9. Stanova Stanztechnik GmbH 2019 www.stanova.de

10. Uwe Heidler 2013 Masterthesis: Untersuchung des Verhaltens von PVC bei spanloser Bearbeitung (Schnittwertanalyse beim Stanzen) und Validierung der Stanzpresse RAPID: Bestimmen der Leistungsmerkmale der Presse und Beurteilung der Stanzergebnisse hinsichtlich eines gratfreien Schnittes (Wildau: TH Wildau)

11. Fritz A H 2018 Fertigungstechnik (Springer-Lehrbuch) 12th edn (Berlin, Heidelberg: Springer Berlin Heidelberg)

12. Mrad K 2019 Masterthesis: Konzeption, Konstruktion und Fertigung eines DemoStanzwerkzeuges zur Visualisierung der Gratentstehung bei Polymeren mit anschließender Analyse der vorhandenen Teilprozesse (Berlin: HTW Berlin)

13. Beier H-M 1999 Handbuch Entgrattechnik: Wegweiser zur Gratminimierung und Gratbeseitigung für Konstruktion und Fertigung (München: Hanser) 